\title{
Evaluation of the reactivity, selectivity and lifetime of hydrotalcite-based catalysts using isopropanol as probe molecule
}

\author{
Zoulikha Abdelsadek ${ }^{1,2} \cdot$ Sergio Gonzalez-Cortes ${ }^{3} \cdot$ Feroudja Bali $^{2}$. \\ OuizaCherifi $^{2} \cdot$ Djamila Halliche $^{2} \cdot$ Patrick J. Masset $^{4}{ }^{\circledR}$
}

Received: 6 September 2021 / Accepted: 15 December 2021 / Published online: 4 January 2022

(c) The Author(s) 2022

\begin{abstract}
Hydrotalcite catalysts derived from $\mathrm{NiAl}$ and NiAlMg mixed oxides were successfully prepared by coprecipitation at a constant $\mathrm{pH}$ of 11 . Physicochemical methods were investigated to determine their structural and textural properties. Using isopropanol as a probe molecule, the acid-base properties of the catalysts were investigated, and the evaluation of reactivity, selectivity and lifetime was established.
\end{abstract}

Keywords Hydrotalcite - Structural characterization · Isopropanol probe reactions · Acid-base properties

\section{Introduction}

Hydrotalcite is the generic name for isomorphic compounds of general formula $\mathrm{Mg}_{6} \mathrm{Al}_{2}(\mathrm{OH})_{16} \mathrm{CO}_{3} \cdot 4 \mathrm{H}_{2} \mathrm{O}$. Hydrotalcite-type anionic clays, layered double hydroxides (LDHs) containing exchangeable anions belong to materials that have attracted much attention in recent years. The structure of the layered double hydroxides can be visualized as the structure of brucite, $\mathrm{Mg}(\mathrm{OH})_{2}$. The brucite phase is constituted

Zoulikha Abdelsadek

z.abdelsadek@univ-boumerdes.dz

$\triangle$ Patrick J. Masset

patrick.masset@tu.koszalin.pl

1 Institute of Electrical and Electronics Engineering, University of M'hamed-Bougara, Independence Avenue, 35000 Boumerdès, Algeria

2 Laboratory of Chemistry and Natural Gas, Faculty of Chemistry, USTHB, El-Alia, B.P. 32, 16111 Bab-Ezzouar, Algiers, Algeria

3 Inorganic Chemistry Laboratory, Department of Chemistry, University of Oxford, South Parks Road, Oxford OX1 3QR, UK

4 Faculty of Mechanical Engineering, Koszalin University of Technology, ul. Śniadeckich 2, 75-453 Koszalin, Poland 
of octahedrons with six $\mathrm{OH}^{-}$groups each surrounded by $\mathrm{Mg}^{2+}$ ions. Sheets are then constituted by the replication of octahedrons. For derived hydrotalcite structures, a part of $\mathrm{Mg}^{+2}$ of the brucite is replaced by divalent and trivalent cations, where their atomic radius must be close to $\mathrm{Mg}^{2+}$ radius $(r=0.65 \AA$ ). The substitution leads to an excess of positive charges in the hydroxide layers, which are compensated by anions located in interlayer interspaces. The general chemical formula of LDHs is $\left[\mathrm{M}_{1-x}{ }^{2+} \mathrm{M}_{x}^{3+}(\mathrm{OH})_{2}\right]^{\mathrm{x}+}\left[\mathrm{A}^{\mathrm{n}-}\right]_{x / n} \cdot \mathrm{mH}_{2} \mathrm{O}$, with $\mathrm{M}^{2+}$ and $\mathrm{M}^{3+}$ are divalent and trivalent metals, $\mathrm{A}^{\mathrm{n}-}$ is an exchangeable interlayer anion such as $\mathrm{CO}_{3}{ }^{2-}, \mathrm{NO}_{3}{ }^{-}, \mathrm{Cl}^{-}$...etc. and $\mathrm{x}$ is the molar fraction ratio $\frac{M^{3+}}{M^{3+}+M^{2+}}$, respectively. The value of $\mathrm{x}$ is an important parameter to obtain a pure hydrotalcite structure with a good crystallinity. It has been reported that this is obtained only in the range $0.2 \leq x \leq 0.33$. When $\mathrm{x}$ takes a value higher than 0.33 , the gibbsite phase $\mathrm{Al}(\mathrm{OH})_{3}$ forms. Likewise, for low values of $\mathrm{x}$, i.e., $x<0.2$, the brucite phase $\mathrm{Mg}(\mathrm{OH})_{2}$ is stable $[1,2]$.

Different preparation methods of the hydrotalcites were investigated to tune their physical and chemical properties in order to apply them in specific applications. However, the coprecipitation process remains the best synthesis approach for the following reasons $[3,4]$ :

- Easy and friendly condition method,

- Cost-effective,

- High reproducibility,

- High production rate and easily scalable,

- Good dispersion of the active phase.

Several textural and structural properties of non-calcined and calcined hydrotalcite phases as nanomaterials have been applied in a wide variety of fields such as medicine, pharmaceutical, biotechnology, electronic, environment, catalysis and catalysts system (Fig. 1) [1].

Recently, oxides obtained by calcination of hydrotalcite have attracted much attention as catalytic system for applications, such as natural gas conversion and production of hydrogen by dry reforming of methane [5, 6], Friedel Craft reaction [7], methanol synthesis [8], etc. The calcination of hydrotalcites at sufficiently high temperatures leads to their dehydration, which is accompanied by de-hydroxylation and then decarboxylation reactions. It ends up with the collapse of the lamellar structure. In addition, mixed oxide phases are obtained at temperatures beyond $450{ }^{\circ} \mathrm{C}$. The following properties can be highlighted from the combination of metal oxides $[1,6$, 8-10]:

- Stable phases with a significant specific surface (between 100 and $300 \mathrm{~m}^{2} / \mathrm{g}$ ),

- Tunable acidic/basic and redox properties,

- Homogeneous dispersion of the active phase.

The catalytic activity and selectivity of the catalyst are closely related to its acid-base, redox properties, textural and structural features resulting from the synthesis conditions. Several probe molecules like $\mathrm{CO}_{2}$ and $\mathrm{NH}_{3}$ were used to 


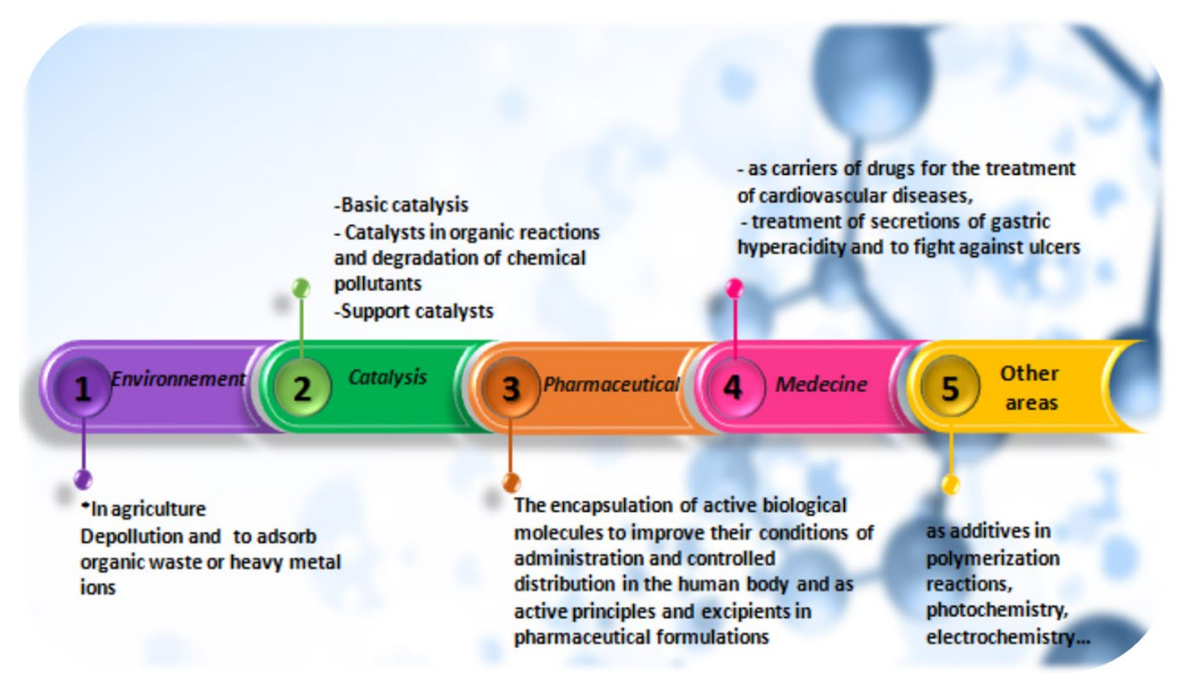

Fig. 1 Different applications of hydrotalcite

characterize the basic and acidic properties of the solids surface, respectively. The conversion of alcohol as catalytic test reaction has been intensively investigated and used to characterize and evaluate the acid-base character of solid catalysts [11, 12]. Most of the attention has been paid to targeted molecules (e.g., isopropanol) that are transformed into products depending on the nature of the available reactive centers onto the heterogeneous catalyst surface. Such reactions have the advantage of being simple and easy to be followed through the quantification of conversion rates. In addition, it can be performed at relatively low temperatures. In contact with an acidic or basic solid, the isopropanol probe molecule may undergo mainly two types of competitive elimination reactions: (i) dehydration, which yields propylene and takes place on acid sites of the catalyst. The formation of di-isopropyl is also possible as a product of the dehydration of propylene and (ii) dehydrogenation reaction produces acetone and hydrogen and occurs in basic sites [13-15] (Fig. 2). The yield and selectivity of products for isopropanol transformation depend on the acid-base features of catalytic surface, which constitutes a well-suited probe molecule in the design of advanced catalysts.

For each application, especially for catalysis applications, the acid-base properties of the catalysts are key parameters regarding their reactivity, selectivity and lifetime. There is strong incentive to enhance solid base properties of catalysts in order to improve their catalytic activity for reactions, such as alkylation, isomerization and Knoevenagel condensation reaction under specific friendly experimental conditions. Materials like zeolites, alkaline earth, basic resin, nickel ferrite spinel, oxides ( $\mathrm{ZnO}$, $\mathrm{MgO}$ ), vanadium-containing catalysts and modified carbon have already been investigated for these reactions and isopropanol transformation [16-18].

Recently, there has been a great interest in the utilization of oxides obtained from calcined hydrotalcites due to their promising strong base properties $[1,10]$. The catalytic properties of oxides derived from hydrotalcite depend mainly on the nature of 

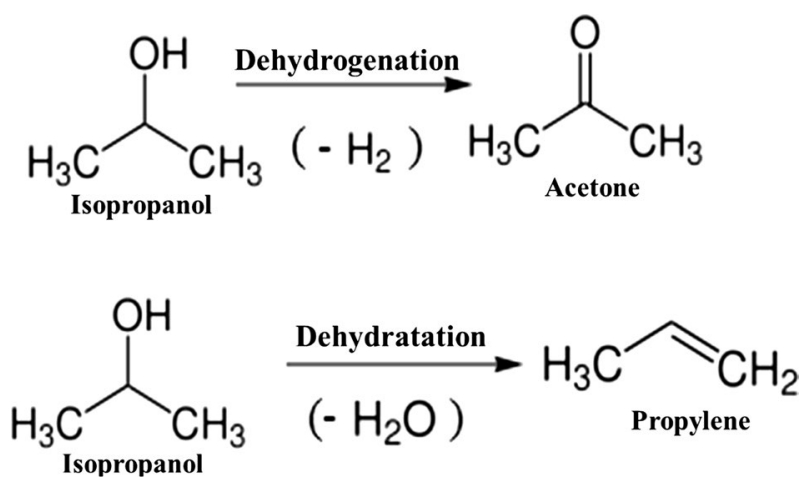

Fig. 2 Pathway of the isopropanol decomposition

divalent and trivalent cations, exchangeable interlayer anions and chemical composition of the hydrotalcite structure and on the activation process which requires acid, base and redox active sites. The decomposition mechanism provides a valuable test reaction to investigate the acid-base properties of materials. Hereafter, the role of $\mathrm{Mg}$ is emphasized in reference to its use in hydrotalcite-based catalysts.

Nakatsuka et al. [19] investigated the activity of calcination products of several $\mathrm{MgAl}-\mathrm{HTc}$ in the polymerization of $ß$-propiolactone. All the HT precursors were calcined at $450{ }^{\circ} \mathrm{C}$ for one hour. According to the authors, $\mathrm{MgO}$ prepared by calcination was not active in the reaction. Moreover, a correlation was found between the activity and the number of basic sites. The inhibition of activity occurring upon $\mathrm{CO}_{2}$ and $\mathrm{H}_{2} \mathrm{O}$ additions confirmed the role of the basic sites in the formation of the polymerization centers. In particular, the authors correlated the activity to the interaction between $\mathrm{MgO}$ and $\mathrm{Al}_{2} \mathrm{O}_{3}$, favoring the formation of suitable basic sites. The basic character was examined for the first time on the compound $\mathrm{MgAl}-\mathrm{CO}_{3}-\mathrm{HT}$, the heat treatment of which allows to obtain oxides of the $\mathrm{MgO}$ type $[1,10]$. The basic properties of $\mathrm{MgO}$ have been widely studied in the literature [1, 20]. Strong basic sites are assigned to $\mathrm{O}^{2-}$ species, while medium basic sites are assigned to $\left(\mathrm{O}^{-}\right)$ groups located near hydroxyl groups. The low basicity is attributed to the $\left(\mathrm{OH}^{-}\right)$ group (Brønsted basicity).

As a conclusion, the activity of $\mathrm{MgAl}$ pure, after calcination at $450{ }^{\circ} \mathrm{C}$, the $\mathrm{XRD}$ analysis showed the presence of mixed oxides: $\mathrm{MgO}$ with $\mathrm{Al}_{2} \mathrm{O}_{3}$. The catalytic activity behavior of this sample via isopropanol decomposition is to produce acetone through strong basic sites [21]. In addition, the combination of $\mathrm{MgO}-\mathrm{Al}_{2} \mathrm{O}_{3}$ promotes the formation of suitable basic sites [1]. The number of defects, and therefore the number of strong basic sites, in the lattice of $\mathrm{MgAl}$ should be expected to increase when increasing the amount of Al introduced. Since Al is more electronegative than $\mathrm{Mg}$, an increase in $\mathrm{Al}$ should increase the average electronegativity of the solid and thus, a decrease in the average electronic density of the unsaturated framework oxygen could be expected reflecting in the basic strength [22].

On the other hand, the propylene formation on the $\mathrm{MgAl}$ hydrotalcite sample can be related to the presence of acid sites associated with $\mathrm{Al}^{3+}$, which is substituted by $\mathrm{Mg}^{2+}$ 
in a $\mathrm{MgO}$ lattice. This substitution may produce local excess of positive charge in the lattice of the oxide which can act as acid sites [22].

The NiAl-HT- and NiMgAl-HT-type hydrotalcite have been studied in many applications such as Friedel craft reaction, aldolization and dry reforming of methane [1, 6]. For the last process, researchers suggest that the basic properties of catalyst derived from hydrotalcite improve the catalytic activity, $\mathrm{CO}_{2}$ activation and consequently the resistance of carbon deposition $[1,23]$.

In the present work, mixed oxides catalysts derived from hydrotalcite of samples $\mathrm{NiAl}-\mathrm{HTc}$ and NiMgAl-HTc were prepared by coprecipitation method, characterized by different chemical-physical techniques and tested in the isopropanol decomposition reaction. The purpose of this work is to evaluate the effect and the influence of the presence of Mg in HDL matrix on textural and structural catalytic properties and acid-base properties of mixed oxides nanomaterials derived from hydrotalcite. The use of isopropanol as probe molecule was considered as a low temperature method under $250{ }^{\circ} \mathrm{C}$, where no structural changes are expected (as it is the case for TPR analysis) and allow the investigation of the composition and especially the use of substitutes of $\mathrm{Ni}$ by $\mathrm{Mg}$ and $\mathrm{Al}$.

\section{Experimental}

\section{Sample preparation}

The catalysts obtained from the hydrotalcite calcined type precursors were prepared by coprecipitation by mixing two solutions: i) a solution containing divalent cations $\mathrm{Ni}\left(\mathrm{NO}_{3}\right)_{2} \cdot 6 \mathrm{H}_{2} \mathrm{O}$ (Merck, 99\%) or with $\mathrm{Mg}\left(\mathrm{NO}_{3}\right)_{2} \cdot 6 \mathrm{H}_{2} \mathrm{O}$ (Merck, 99\%), and trivalent cations $\mathrm{Al}\left(\mathrm{NO}_{3}\right)_{3} \cdot 9 \mathrm{H}_{2} \mathrm{O}$ (Fluka, 98\%) ii) a solution prepared by dissolving an amount of $\mathrm{Na}_{2} \mathrm{CO}_{3}$ (Merck, 98\%) and $\mathrm{NaOH}$ (Merck, 98\%) to adjust the $\mathrm{pH}$. The two solutions were mixed dropwise under vigorous stirring at room temperature and at $\mathrm{pH}$ basic constant ( $\mathrm{pH}$ 11). The final $\mathrm{pH}$ of the total solution was adjusted by adding $\mathrm{NaOH}$ solution (2 M). After the addition of reagents, the obtained gel was aged at $80{ }^{\circ} \mathrm{C}$ in oil bath shaker for $18 \mathrm{~h}$ under gentle stirring. The solid was cooled to room temperature, then filtered and washed with a large amount of deionized water to remove all residuals until getting a solution $\mathrm{pH}$ equal to 7 . The resulting slurry was dried overnight by an oven at $80{ }^{\circ} \mathrm{C}$ under air. The non-calcined synthesized samples were labeled $\mathrm{NiAl}-\mathrm{CO}_{3}$ and $\mathrm{NiMgAl}-\mathrm{CO}_{3}$.

After drying, the solids $\mathrm{NiAl}-\mathrm{CO}_{3}$ and $\mathrm{NiMgAl}-\mathrm{CO}_{3}$ were calcined at $450{ }^{\circ} \mathrm{C}$ for $6 \mathrm{~h}$ using a heating rate of $4{ }^{\circ} \mathrm{C} / \mathrm{min}$ in a muffle furnace. The calcined materials obtained were referred to $\mathrm{NiAl}-\mathrm{CO}_{3}-\mathrm{c}$ and $\mathrm{NiMgAl}-\mathrm{CO}_{3}$-c. The solids were crushed to obtain a fine powder (Fig. 3). 


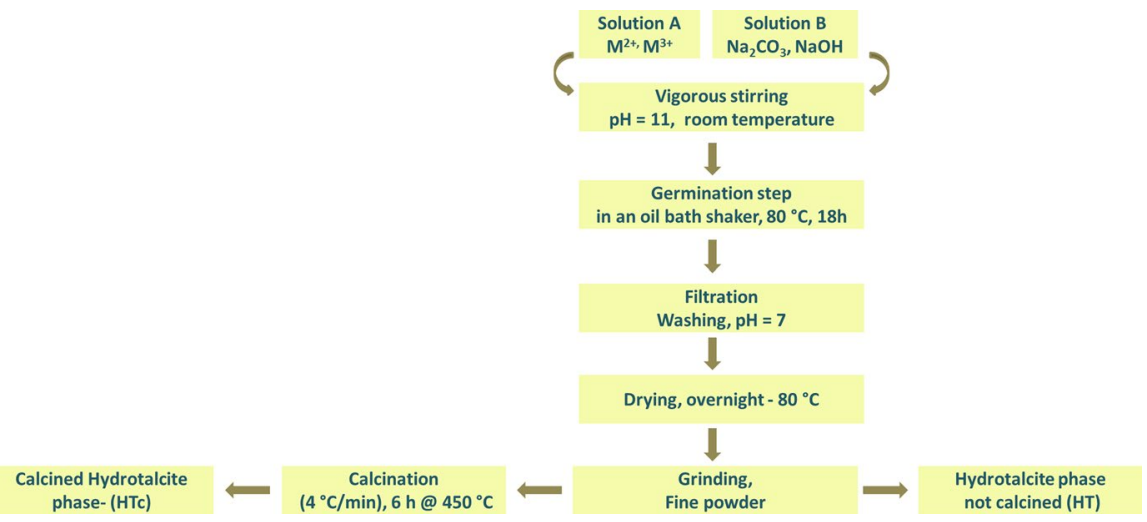

Fig. 3 Scheme of HDLs synthesis

\section{Sample characterization}

\section{Atomic absorption spectroscopy (AAS) analysis}

The chemical composition was determined by Atomic Absorption Spectroscopy (AAS) using Spectro-Analytical Instruments Horiba Jobin-Yvon, Ultima spectrometer; $100 \mathrm{mg}$ of the solids was dissolved in $20 \mathrm{ml}$ of aqua regia and the solution was diluted to $100 \mathrm{ml}$ with distilled water.

\section{X-ray diffraction (XRD) analysis}

Powder X-ray diffraction (XRD) patterns were recorded with Siemens D-501 equipment, using $C u K_{\alpha}$ radiation in the $2 \theta$ range between 10 and $80^{\circ}$. The crystallite size was evaluated using the Scherrer's formula [Eq. (1)] [24, 25].

$$
d_{h k l}=\frac{0.9 \lambda}{\beta_{h k l} \cos \theta}
$$

where $\lambda$ is the wavelength of $C u K \alpha(\lambda=1.5418 \AA), \beta_{h k l}$ is the half-width of the peak, and $\theta$ is the Bragg's diffraction angle.

\section{Brunauer-Emmett-Teller (BET) analysis}

Brunauer-Emmett-Teller (BET) surface area measurements were carried out using a NOVA 2000e volumetric adsorption analyzer at $-196{ }^{\circ} \mathrm{C}$ (liquid nitrogen). Before each measurement, the powder was degassed under vacuum at $150{ }^{\circ} \mathrm{C}$ for $2 \mathrm{~h}$. 


\section{Fourier transform infrared (FTIR) analysis}

Fourier transform infrared (FTIR) spectra were recorded using a Perkin Elmer model number spectrometer. Over 32 scans were taken to improve the signal-to-noise ratio in the wavelength range (400-4000 $\mathrm{cm}^{-1}$ ) with a resolution of $4 \mathrm{~cm}^{-1}$. The analysis was performed on $c a .4 \mathrm{mg}$ of powder mixed with $100 \mathrm{mg}$ of dried spectroscopic $\mathrm{KBr}$ pressed into pellets.

\section{Thermogravimetry analysis (TG) and differential thermal analysis (DTA)}

Thermogravimetry analysis (TGA) and differential thermal analysis (DTA) were performed using a Netzsch STA 409 PC/PG instrument under air as purge gas from room temperature up to $850{ }^{\circ} \mathrm{C}$ with a heating rate of $10{ }^{\circ} \mathrm{C} / \mathrm{min}$ using alumina crucibles.

\section{Scanning electron microscopy analysis (SEM)}

Scanning electron microscopy images (SEM) of the products were recorded on a Hitachi S-4800 instrument equipped with a field emission filament using an acceleration voltage of $5 \mathrm{kV}$ and a working distance of $10 \mathrm{~mm}$.

\section{Transmission electron microscopy analysis (TEM)}

A transmission electron microscopy (TEM) study of the samples was carried out at $200 \mathrm{kV}$ using a Philips CM200 TEM equipped with a LaB6 emitter, an Oxford ISIS EDX super-ultrathin window detector and a Gatan Model 678 Imaging Filter (GIF). The crushed sample dispersed in ethanol solution was vigorously stirred using ultrasound to minimize the deposit of clusters of particles. A droplet of this suspension is then placed on a copper grid covered with a carbon film. Once the grid is ready; SEM analysis can be measured.

\section{Catalytic testing}

The isopropanol decomposition on material catalysts takes place through two pathways: the dehydration, which generally needs acid catalysts or the two types of acidic-basic sites, dehydrogenation is catalyzed by basic sites.

The catalytic tests of transformation of isopropanol (Merck, 99.7\%) were conducted in a fixed bed continuous flow reactor under atmospheric pressure and temperature between 150 and $250^{\circ} \mathrm{C}$, by passing nitrogen gas through a saturator-containing alcohol. The mass of catalyst was approx. $0.02 \mathrm{~g}$, and the flow rate was kept to $0.05 \mathrm{ml} / \mathrm{min}$. The tests were carried out at atmospheric pressure and the saturating vapor of the gaseous propan2-ol reagent $\left(P_{0}=4 \mathrm{mmHg}\right)$ is obtained by bubbling nitrogen $(380 \mathrm{mmHg})$ in liquid propan2-ol placed in a saturator immersed in an ice bath. 
Reactants and reaction products were analyzed by gas chromatography (VARIAN 3350) using a 10\% Carbowax $20 \mathrm{M}$ on Chromosorb 200 column and flame ionization detector.

The conversion of isopropanol ( $\left.\mathrm{Con}_{\text {isop }}\right)$, selectivity of propene $\left(\mathrm{Sec}_{\text {prop }}\right)$ and selectivity of acetone $\left(\mathrm{Sec}_{\mathrm{acet}}\right)$ were estimated using the following formulas:

$$
\begin{aligned}
& \operatorname{Con}_{\text {isop }}(\%)=\frac{\text { Moles of isopropanol converted }}{\text { Moles of isopropanol in feed }} \times 100 \\
& \operatorname{Sec}_{\text {prop }}(\%)=\frac{\text { Moles of propylene produced }}{\text { Moles of isopropanol converted }} \times 100 \\
& \operatorname{Sec}_{\text {acet }}(\%)=\frac{\text { Moles of acetene produced }}{\text { Moles of isopropanol converted }} \times 100
\end{aligned}
$$

\section{Results and discussion}

\section{Characterization of catalyst}

The chemical formula of the synthesized samples was determined by X-ray fluorescence supposing that the carbonates are the only anions in the inter-layer. The number of the carbonates was estimated from the molar ratio $\mathrm{M}^{2+} / \mathrm{M}^{3+}$. The water molecules content $\left(\mathrm{mH}_{2} \mathrm{O}\right)$ was calculated using the formula (Eq. 2):

$$
18 m=\frac{w(a+18 m)}{100}
$$

where $m$ is the number of water molecules in the inter-lamellar space, $a$ is the molecular mass of the anhydrous compound and $w$ the mass loss (\%) of water derived from the thermogravimetric analysis (Fig. 4).

The data of the X-ray fluorescence technique (Table 1) confirm that the $\mathrm{M}^{2+/} \mathrm{M}^{3+}$ ratios were like those estimated from the concentrations of the salts in the initial synthesis solution. This result confirms the complete precipitation of $\mathrm{Ni} /$ $\mathrm{Mg}$ and $\mathrm{Al}$ precursor salts during the synthesis. The results confirm the presence of the transition metals used ( $\mathrm{Ni}, \mathrm{Mg}$ and $\mathrm{Al}$ ) in all hydroxides double lamellar phase (HDL-phases) samples. This indicates that the operating conditions such as the $\mathrm{pH}$, precipitating agent, temperature of the germination phase lead to the precipitation of divalent and trivalent ions under stoichiometric conditions.

The result obtained (Table 1) indicates that the general formula $\left[\mathrm{M}_{1-x}{ }^{2+} \mathrm{M}_{x}^{3+}(\mathrm{OH})_{2}\right]^{\mathrm{x}+}\left[\mathrm{A}^{\mathrm{n}-}\right]_{x / n} \cdot \mathrm{mH}_{2} \mathrm{O}$ enables the synthesis of HDL-phases with different divalent and trivalent metals where $0.22 \leq x \leq 0.33[1,6,26]$. The mass changes of the samples type hydrotalcites were derived from TGA/DTA analyses. The analysis showed the typical results reported in the literature of the thermal decomposition of hydrotalcite as materials [1, 6, 27]. According to Table 2 and 

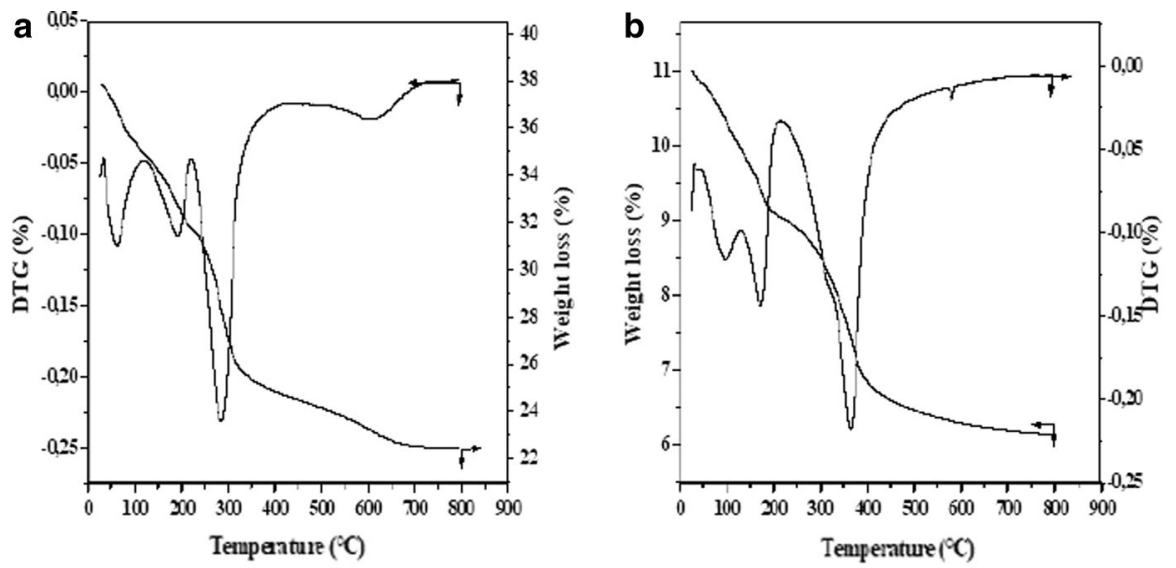

Fig. 4 TGA/DTA for a NiMgAl-CO 3 and $\mathbf{b} \mathrm{NiAl}-\mathrm{CO}_{3}$

Fig. 2, the evolution of the thermal decomposition of hydrotalcite phases reveals three steps of the mass losses. The first step presents the moving of the physically absorbed molecules on the outer surface of the HDL-phases at $100{ }^{\circ} \mathrm{C}$ corresponding to 4 and $5 \mathrm{wt} \%$ for $\mathrm{NiMgAl}-\mathrm{CO}_{3}$ and $\mathrm{NiAl}-\mathrm{CO}_{3}$, respectively. The second step designs the elimination of inter-lamellar water by de-hydroxylation phenomena accompanied by the elimination of nitrates molecules at around $200-205{ }^{\circ} \mathrm{C}$ accounting 15-16 wt $\%$. The third and the last step occurs at higher temperatures $\left(300-320{ }^{\circ} \mathrm{C}\right.$ ), which is characterized by the elimination of the carbonates in the layer space with mass loss corresponding to 35 and $31 \mathrm{wt} \%$ for $\mathrm{NiMgAl}-\mathrm{CO}_{3}$ and for $\mathrm{NiAl}-\mathrm{CO}_{3}$, respectively.

The BET surface area $\left(S_{\mathrm{BET}}\right)$ non-calcined and calcined specimens at $450{ }^{\circ} \mathrm{C}$ materials are summarized in Table 2. For the two samples, the surface area after

Table 1 Chemical composition of the prepared samples

\begin{tabular}{lllllll}
\hline Sample name & $x=\frac{n \mathrm{M}^{3+}}{n\left(\mathrm{M}^{2+}+\mathrm{M}^{3+}\right)}$ & ratio $\frac{\mathrm{M}^{2+}}{\mathrm{M}^{3+}}$ & $\mathrm{MgO}(\%)(\%)$ & $\mathrm{NiO}(\%)$ & $\mathrm{Al}_{2} \mathrm{O}_{3}(\%)$ & Formula \\
\hline $\mathrm{NiMgAl}-\mathrm{CO}_{3} \mathrm{c}$ & 0.33 & 1.97 & 26.19 & 23.19 & 32.96 & $\begin{array}{c}{\left[\mathrm{Ni}_{0.22} \mathrm{Mg}_{0.45} \mathrm{Al}_{0.33}\right]} \\
\left(\mathrm{CO}_{3}\right)_{0.165} \cdot 0.15 \mathrm{H}_{2} \mathrm{O}\end{array}$ \\
$\mathrm{NiAl}-\mathrm{HT}-\mathrm{CO}_{3}-\mathrm{c}$ & 0.34 & 1.91 & - & 67.28 & 24.56 & $\begin{array}{c}{\left[\mathrm{Ni}_{0.65} \mathrm{Al}_{0.34}\right]} \\
\left(\mathrm{CO}_{3}\right)_{0.170} \cdot 0.24 \mathrm{H}_{2} \mathrm{O}\end{array}$ \\
\hline
\end{tabular}

Table 2 TG results and specific surface of two prepared samples

\begin{tabular}{|c|c|c|c|c|c|c|c|c|}
\hline \multirow[t]{2}{*}{ Sample } & \multicolumn{2}{|c|}{ First stage } & \multicolumn{2}{|c|}{ Second stage } & \multicolumn{2}{|c|}{ Third stage } & \multicolumn{2}{|c|}{$S_{\mathrm{BET}}\left(\mathrm{m}^{2} / \mathrm{g}\right)$} \\
\hline & $\mathrm{Wt} \%$ & $\begin{array}{l}\text { Tempera- } \\
\text { ture }\left({ }^{\circ} \mathrm{C}\right)\end{array}$ & $\mathrm{Wt} \%$ & $\begin{array}{l}\text { Tempera- } \\
\text { ture }\left({ }^{\circ} \mathrm{C}\right)\end{array}$ & $\mathrm{Wt} \%$ & $\begin{array}{l}\text { Tempera- } \\
\text { ture }\left({ }^{\circ} \mathrm{C}\right)\end{array}$ & Precursor & Calcinated \\
\hline $\mathrm{NiMgAl}-\mathrm{CO}_{3}$ & 4 & 100 & 16 & 205 & 35 & 320 & 94 & 169 \\
\hline $\mathrm{NiAl}-\mathrm{CO}_{3}$ & 5 & 100 & 15 & 200 & 31 & 300 & 32 & 117 \\
\hline
\end{tabular}


calcination is greater than the precursor. This result is due to the occurrence of three phenomena: dehydration, de-hydroxylation and decarbonation during thermal treatment. The sample contains $\mathrm{Mg}$ (i.e., $\mathrm{NiMgAl}-\mathrm{CO}_{3}$ ) and shows high specific area after and before calcination compared to $\mathrm{NiAl}-\mathrm{CO}_{3}$ due to dispersive effects, which have already been investigated and reported in the literature [1, 9, 28].

Usually, a high surface area leads to a good catalytic activity due to the high dispersion of active phase. In the present work, non-calcined NiMgAl-HT and even after calcination exhibits a large surface area compared to calcined and non-calcined $\mathrm{NiAl-HTc}$. This result is explained by the incorporation of $\mathrm{Mg}$ into NiAl hydrotalcite matrix. The presence of $\mathrm{Mg} 2+$ cation increases the specific surface area and modifies the pore diameter. Furthermore, the crystallite size's phase presented by $\mathrm{NiMgAl}-\mathrm{HTc}$ resulted smaller than that for NiAl-HTc as confirmed by XRD analysis. This result agrees with previous findings from Crivello et al. and Abdelsadek et al. $[28,29]$ who determined that the $\mathrm{Mg}^{2+}$ cation has a dispersive effect over the other components of the catalyst. In the case of the solid NiMgAl-HTc, a great activity or catalytic behavior was obtained with larger surface area influence for the isopropanol decomposition and dry reforming of methane [29].

Figure 3 shows the XRD patterns of HDL precursor phases and calcined samples. The diffractograms of the precursor samples $\mathrm{NiMgAl}-\mathrm{CO}_{3}$ and $\mathrm{NiAl}-\mathrm{CO}_{3}$ show the presence of two main peaks allocated to the layered double hydroxides phases of hydrotalcite: peaks intense sharp symmetric reflections for (003), (006), (110) and (113) planes and asymmetric broad peaks for (012), (015) and (018). No other phase was detected which indicates that the divalent and trivalent ions were completely introduced into hydrotalcite structure under the selected experimental conditions. This enables synthesizing hydrotalcite phases with mixtures of different divalent and trivalent cations in the right range of metallic composition. After calcination at $450{ }^{\circ} \mathrm{C}$, the XRD patterns (Fig. 5) show clearly that the structure was modified. The hydrotalcite phases were decomposed to form metallic oxides. The $\mathrm{NiO}$ phase was detected for the $\mathrm{NiMgAl}-\mathrm{CO}_{3}-\mathrm{c}$ and $\mathrm{NiAl}-\mathrm{CO}_{3}-\mathrm{c}$
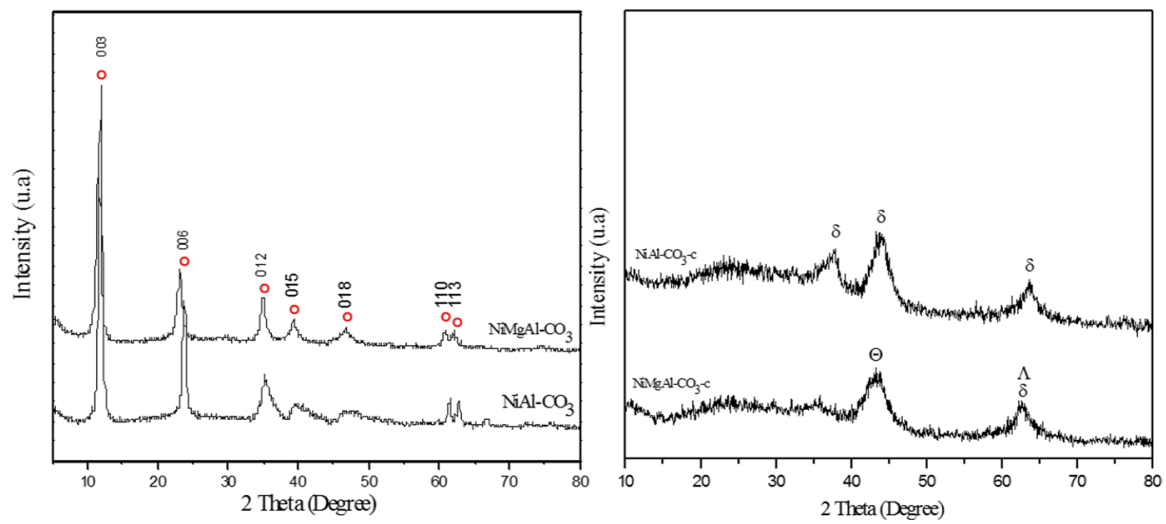

Fig. 5 X-ray diffractograms of precursor $\mathrm{NiMgAl}-\mathrm{CO}_{3}$ and $\mathrm{NiAl}-\mathrm{CO}_{3}$ and calcined sample NiMgAl- $\mathrm{CO}_{3}$-c and $\mathrm{NiAl}-\mathrm{CO}_{3}$-c. (o): HDL phase, $\delta \mathrm{NiO}, \Lambda \mathrm{MgO}$ and $\Theta \mathrm{NiO}-\mathrm{MgO}$ 


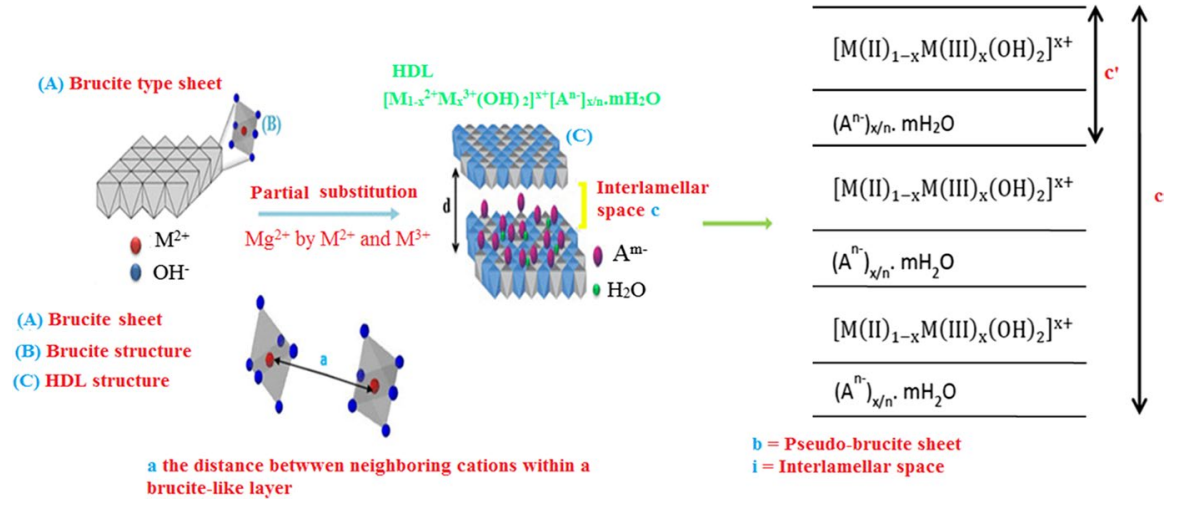

Fig. 6 HDL structure and structural parameters a and c

Table 3 Crystallographic parameter a and c with crystallite size of synthesized HDL

\begin{tabular}{llllcccc}
\hline Sample name & $\mathrm{d}_{003}(\AA)$ & $\mathrm{c}=\mathrm{d}_{003}(\AA)$ & $\mathrm{a}=2 \mathrm{~d}_{110}(\AA)$ & \multicolumn{3}{c}{ Crystallite size’ phases $(\AA)$} & \\
\cline { 5 - 8 } & & & & $003^{\mathrm{a}}$ & $110^{\mathrm{a}}$ & $\mathrm{MgO}$ & $\mathrm{NiO}$ \\
\hline $\mathrm{NiMgAl} \mathrm{CO}_{3}$ & 7.60 & 22.74 & 3.04 & 95 & 110 & 22 & 25 \\
$\mathrm{NiAl}_{-\mathrm{CO}_{3}}$ & 7.70 & 22.96 & 3.04 & 156 & 208 & - & 35 \\
\hline
\end{tabular}

${ }^{\text {a }}$ Hydrotalcite phase

calcined samples, plus $\mathrm{MgO}$ in the case of $\mathrm{NiMgAl}-\mathrm{CO}_{3}-\mathrm{c}$. However, alumina $\mathrm{Al}_{2} \mathrm{O}_{3}$ was probably formed but was not detected by XRD analysis since it is an amorphous phase at this temperature. No ternary or mixed oxides were detected by XRD analysis.

The first reflection of the plane (003) is characteristic of the successive stacking of the layers along the axis c. The mesh parameter (c) is easily calculated since it is equal to $3 \mathrm{c}^{\prime}\left(\mathrm{c}^{\prime}\right.$ corresponding to the sum of the thickness of a layer of brucite $(4.8 \AA)$ and the inter-lamellar domain, i.e., the inter-reticular distance family plans (003). The mesh parameter (a) corresponds to the distance between neighboring cations within a brucite-like layer and is defined from the distance $(a=2 \times \mathrm{d} 110)$. The a and c parameters obtained for the HDL synthesized phases are very similar to the value reported in the literature $[1,4,30]$ (Fig. 6).

The $\mathrm{d}_{003}$, which presents inter-lamellar distance calculated for the carbonates hydrotalcite phases prepared samples is close to the value published $(7.8 \AA)[1,31]$. The crystallite size in a direction and c direction for the two materials is presented in Table 3.

The results obtained show that the dimensions in the a-direction are larger than that in c-direction which reveals the plate-like form of the hydrotalcite crystal phase. After calcination, the estimation of the crystallite sizes of the oxides $\mathrm{NiO}$ and $\mathrm{MgO}$ was estimated and is provided in Table 3. The crystallite sizes of the oxides (NiO, $\mathrm{MgO}$ ) are lower than HDL precursor phase. It explains that the specific surfaces of 

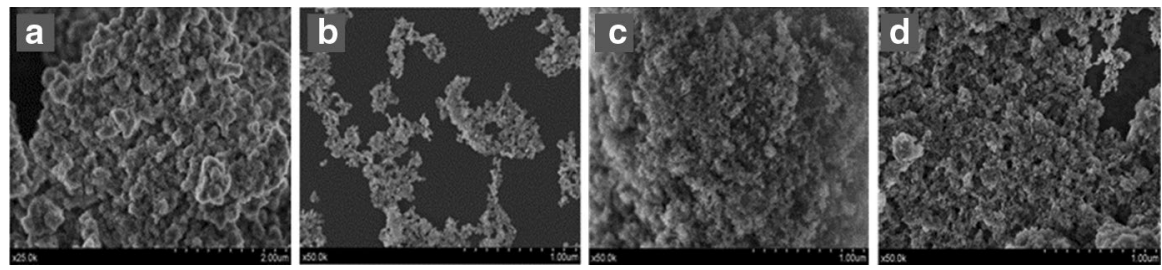

Fig. 7 SEM images of NiMgAl- $\mathrm{CO}_{3}(\mathbf{a}, \mathbf{c})$ and $\mathrm{NiAl}-\mathrm{CO}_{3}(\mathbf{b}, \mathbf{d})$ with a, b: non-calcined phases and c, d: calcined phases
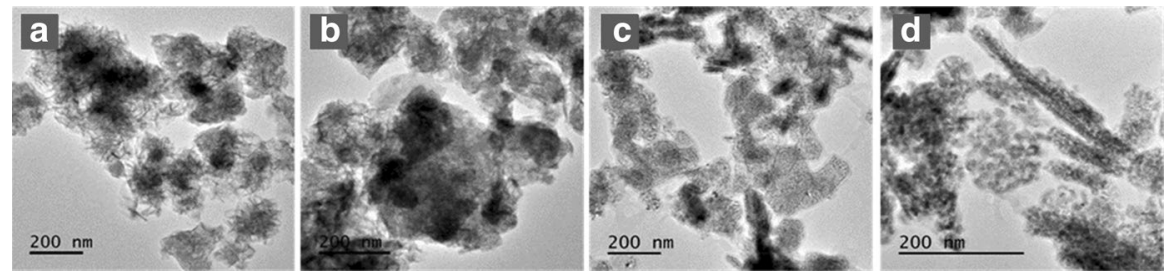

Fig. 8 TEM images of NiMgAl-CO $(\mathbf{a}, \mathbf{c})$ and $\mathrm{NiAl}-\mathrm{CO}_{3}(\mathbf{b}, \mathbf{d})$ with a, b: non-calcined phases and c, d: calcined phases

the calcined samples $\mathrm{NiMgAl}-\mathrm{CO}_{3}$ and $\mathrm{NiAl}-\mathrm{CO}_{3}$ are larger than the HDL precursor phases (Table 2). In addition, compared to the two solids $\mathrm{NiMgAl}-\mathrm{CO}_{3}$ and NiAl$\mathrm{CO}_{3}$, the non-calcined and calcined $\mathrm{NiMgAl}-\mathrm{CO}_{3}$ show high surface area than noncalcined and calcined $\mathrm{NiAl}-\mathrm{CO}_{3}$. Magnesium influences the germination and crystal growth step and leads to the formation of the nano-sized crystallites, fine small particles and also increases the specific surface of the compound [28, 32]. This result agrees with the results obtained by BET analysis (Tables 2 and 3).

The morphology of the samples prior to calcination was investigated by SEM and TEM analyzes. Figures 7 and 8 show the SEM and TEM images, respectively, of HDL phases synthesized for the samples non-calcined $\mathrm{NiMgAl}-\mathrm{CO}_{3}$ and $\mathrm{NiAl}-$ $\mathrm{CO}_{3}$. SEM and TEM images of the NiAl- $\mathrm{CO}_{3}$ show that the morphology of HDL phases prepared precursor confirms the presence and accumulation of fine nanoparticles of regular shape with inter-platelet porosity. The corresponding micrograph of the compound $\mathrm{NiMgAl}-\mathrm{CO}_{3}$ exhibits special features. It seems that the fine particles aggregate and connect to each other giving rise to a specific arrangement like a «rose sand» (Figs. 7a and8a). This result was confirmed by the SEM images of this sample. Fine particles evidenced by SEM and TEM techniques correspond only to hydrotalcites phases precursor. This observation agrees with the results obtained by XRD analysis.

After calcination, the SEM (see Fig. 7c, d) and TEM (see Fig. 8c, d) images for the two calcined materials $\mathrm{NiMgAl}-\mathrm{CO}_{3}-\mathrm{c}$ and $\mathrm{NiAl}-\mathrm{CO}_{3}-\mathrm{c}$ show the presence of the compact aggregates owing to the transformed hydrotalcite structure during thermal treatment. These aggregates are related to the mixture of oxides phases as revealed by XRD analysis (see Fig. 3, Table 3). FTIR spectra of non-calcined $\mathrm{NiMgAl}-\mathrm{CO}_{3}$ and NiAl- $\mathrm{CO}_{3}$ specimens are shown in Fig. 9a. The spectrum of the 

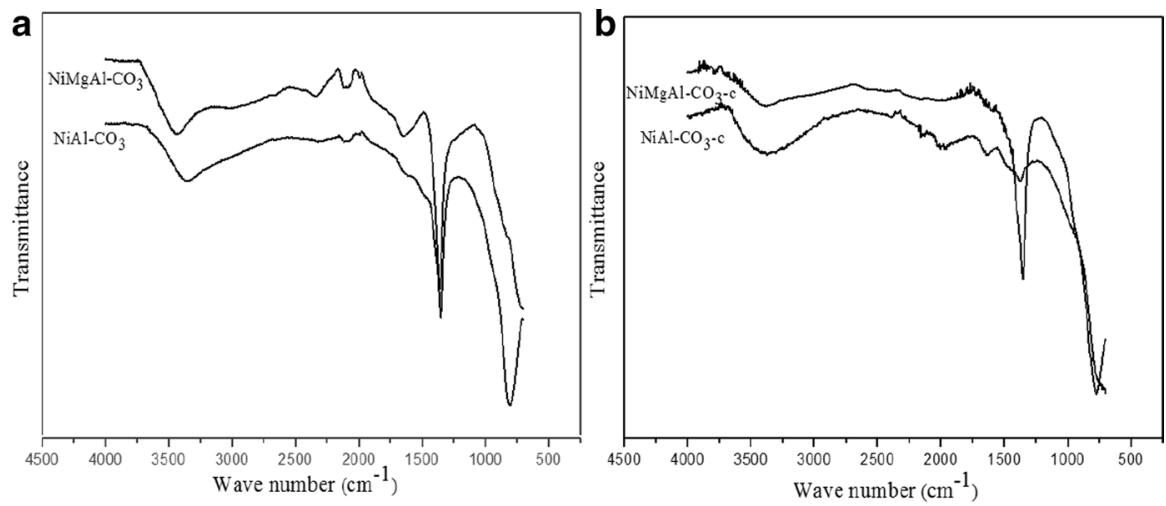

Fig. 9 Infrared spectra of a non-calcined and $\mathbf{b}$ calcined samples $\mathrm{NiMgAl}-\mathrm{CO}_{3}-\mathrm{c}$ and $\mathrm{NiAl}-\mathrm{CO}_{3}-\mathrm{c}$

two non-calcined samples exhibits typical features of the non-calcined hydrotalcite phases non-calcined already reported in the literature [33]. Table 4 summarizes the different vibration bands before and after calcination of the solids $\mathrm{NiMgAl}-\mathrm{CO}_{3}$ and $\mathrm{NiAl}-\mathrm{CO}_{3}$.

After calcination, the decrease in the all intensities of the different bands was observed owing to the treatment thermal at $450{ }^{\circ} \mathrm{C}$ : dehydration, de-hydroxylation and decarbonation (Fig. 5b, Table 4). It notices the presence of vibration bands at $1380 \mathrm{~cm}^{-1}$ characteristic to the carbonates. These are the trace amounts of the remaining carbonates which are called «residual carbonates» and they are responsible for memory effect, specific properties of hydrotalcites materials calcined at temperature $\leq 450{ }^{\circ} \mathrm{C}[1,34]$. This result is in good agreement with the XRD data.

Raman assignment peaks (Fig. 10) of synthesized materials showed the same behavior to HDL phases structure described in literature reports [35] (Fig. 10). Broad stretching vibrations assigned at $3400-3600 \mathrm{~cm}^{-1}$ are attributed to $\mathrm{OH}$ vibrations of physisorbed water molecules. Stretching vibrations modes at 2447 and $2441 \mathrm{~cm}^{-1}$ for both solids $\mathrm{NiMgAl}-\mathrm{CO}_{3}$ and $\mathrm{NiAl}-\mathrm{CO}_{3}$, respectively, are associated with vibrations of $\mathrm{OH}$ units with metal. Raman bands at $1650 \mathrm{~cm}^{-1}$ for $\mathrm{NiAl}-\mathrm{CO}_{3}$ and $1654 \mathrm{~cm}^{-1}$ for $\mathrm{NiMgAl}-\mathrm{CO}_{3}$ are ascribed to inter-lamellar water deformation mode. The bands at $671 \mathrm{~cm}^{-1}\left(\mathrm{NiAl}-\mathrm{CO}_{3}\right)$ and $702 \mathrm{~cm}^{-1}\left(\mathrm{NiMgAl}-\mathrm{CO}_{3}\right)$ are designated to the $\gamma_{4} \mathrm{CO}_{3}$ in the interlayer. The others bands $\left(545,404\right.$ and $\left.364 \mathrm{~cm}^{-1}\right)$ for $\mathrm{NiAl}-\mathrm{CO}_{3}$ and $\left(553,450,396\right.$, and $\left.348 \mathrm{~cm}^{-1}\right)$ for $\mathrm{NiMgAl}-\mathrm{CO}_{3}$ are considered to the linkage Al-O-Al, Al-O-Ni in the two solids $\mathrm{NiMgAl}-\mathrm{CO}_{3}$ and $\mathrm{NiAl}-\mathrm{CO}_{3}$ in addition $\mathrm{Al}-\mathrm{O}-\mathrm{Mg}$ in the sample $\mathrm{NiMgAl}-\mathrm{CO}_{3}$.

\section{Catalytic testing results}

Isopropanol is a test molecule often used to detect acid-base features of materials and especially of catalysts. The transformation of isopropanol can lead to essential products such as acetone, propylene and in a lower degree di-isopropyl ether. The production of acetone by isopropanol dehydrogenation is related to the presence 


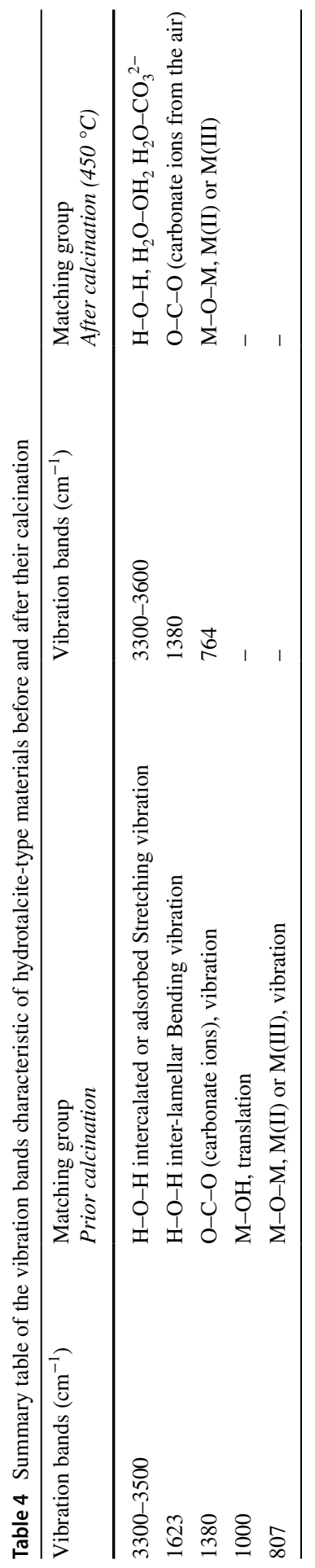



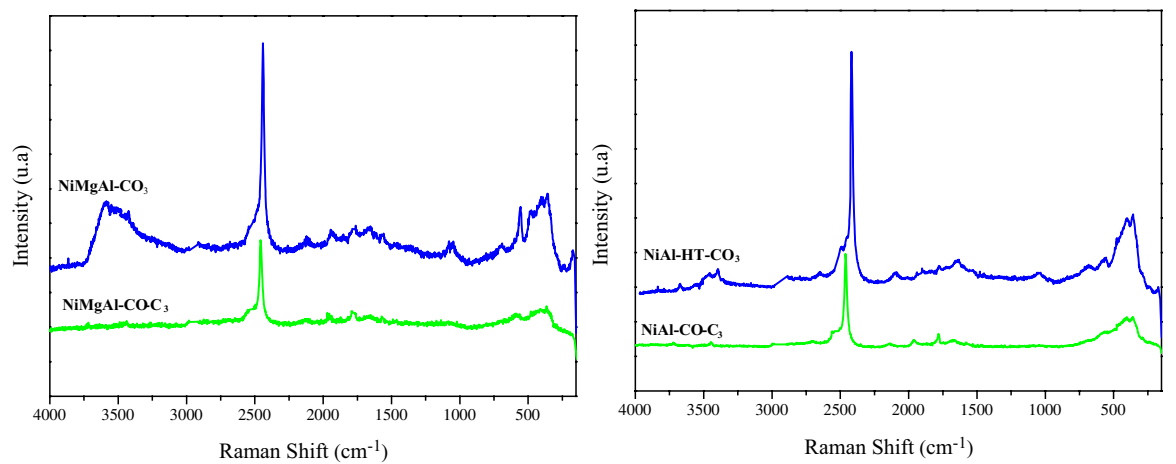

Fig. 10 Raman spectra of non-calcined $\left(\mathrm{NiMgAl}-\mathrm{CO}_{3}\right.$ and $\left.\mathrm{NiAl}-\mathrm{CO}_{3}\right)$ and calcined samples (NiM$\mathrm{gAl}-\mathrm{CO}_{3}$-cand $\mathrm{NiAl}-\mathrm{CO}_{3}$-c)

of basic sites, whereas the formation of propylene occurs via acid sites (Fig. 2). The results of isopropanol conversion, selectivity into acetone and propylene were investigated at different temperatures over the two catalysts $\mathrm{NiMgAl}-\mathrm{CO}_{3}-\mathrm{c}$ and $\mathrm{NiAl}-\mathrm{CO}_{3}$-c and the results are depicted in Fig. 11.

According to the experimental results, both catalysts show a good catalytic activity for the isopropanol decomposition with different acid-base, redox properties depending on the composition of the samples NiAl-HTc and NiMgAl-HTc and support the presence of $\mathrm{Mg}$ in NiAl-HT matrix. Without minimizing the role of $\mathrm{Ni}$ in the catalytic properties of hydrotalcites especially for methane reforming process (dry reforming, vapor-reforming and oxidation) [1, 36, 37], it must be emphasized that $\mathrm{NiMgAl}-\mathrm{HTc}$ exhibits a greater catalytic activity despite its lower amount of $\mathrm{Ni}$ relative to NiAl-HTc. Interestingly, NiAl-HTc also presents basic properties. Acetone is the major product for NiAl-HTc and NiMgAl-HTc catalysts; however the last formulation favors this product owing to the presence of $\mathrm{Mg}^{2+}$ cation. This result is consistent with previous investigations of Abdelsadek et al. [29], who reported that the higher concentration of basic sites in $\mathrm{NiMgAl}$ hydrotalcite samples enhanced the catalytic activity.

The first observation is that the hydrotalcite phases exhibited a notable catalytic activity with respect to the reaction of the decomposition of isopropanol even at low reaction temperature compared to other materials like spinel ferrites which are only active beyond $200{ }^{\circ} \mathrm{C}$ [38]. The conversion of isopropanol in both formulations is influenced by the rise in the temperature of reaction. The increase in the reaction temperature results in an increase in the transformation of isopropanol to reach at $250{ }^{\circ} \mathrm{C}$ the maximum conversion. The isopropanol conversion for the sample NiMgAl- $\mathrm{CO}_{3}-\mathrm{c}$ resulted higher than that for the binary $\mathrm{NiAl}-\mathrm{CO}_{3}-\mathrm{c}$. For instance, the conversion of isopropanol at $175{ }^{\circ} \mathrm{C}$ reaches $93 \%$ and $85 \%$ for $\mathrm{NiMgAl}-\mathrm{CO}_{3}$ and $\mathrm{NiAl}-\mathrm{CO}_{3}$ catalysts, respectively. This result reveals that the decomposition of isopropanol is more active over $\mathrm{NiMgAl}-\mathrm{CO}_{3}$ catalyst.

At higher conversion rate, it is generally no longer the kinetic factors that influence the distribution of the reaction products and it becomes very difficult to give a precise meaning to the observed selectivity. The trends can only be established by 
Fig. 11 Isopropanol catalytic decomposition on $\mathrm{NiAl}-\mathrm{CO}_{3}-\mathrm{c}$ and $\mathrm{NiMgAl}-\mathrm{CO}_{3}-\mathrm{c}$ at different reaction temperatures. a Isopropanol conversion, $\mathbf{b}$ acetone selectivity and $\mathbf{c}$ propylene selectivity (the tests were conducted at atmospheric pressure and the saturating vapor of the gaseous propan2-ol reagent $\left(\mathrm{P}_{0}=4 \mathrm{mmHg}\right)$ is obtained by bubbling nitrogen $(380 \mathrm{mmHg})$ in liquid propan2-ol placed in a saturator immersed in an ice bath)

extrapolation of the results obtained at low conversion rate and it is for this purpose that the reaction has been studied at temperatures lower than or equal to $250{ }^{\circ} \mathrm{C}$.

The isopropanol transformation on $\mathrm{NiMgAl}-\mathrm{CO}_{3}$ and $\mathrm{NiAl}-\mathrm{CO}_{3}$ catalysts lead to only acetone and propylene, whereas di-isopropyl ether was not detected. Acetone, product of the dehydration reaction of isopropanol, needs the presence of basic sites, while propylene product is formed by the dehydration reaction in the presence of acid sites. The literature results indicate that the dehydration of the alcohol to acetone is able of revealing the basic character of the catalysts. However, this last point is still controversial, because the acetone formation can also involve an oxidation-reduction mechanism, particularly at low temperatures [21, 39]. The activity of the isopropanol transformation shows that the acetone formation increases with the rise of the temperature reaction and it is favored by the presence of $\mathrm{Mg}$ in the HDL structure $\left(\mathrm{NiMgAl}-\mathrm{CO}_{3}-\mathrm{c}\right)$.

\section{Role of $\mathrm{Mg}$ and $\mathrm{Al}$ in the hydrotalcite-derived catalysts}

According to the literature, a study about vanadium oxides supported on hydrotalcite type $(\mathrm{V} / \mathrm{MgAl}$, with different amounts of $\mathrm{Mg}(1.00,0.89$ and 0.50$)$ was tested for isopropanol transformation reaction. It showed that the sample with the largest content of $\mathrm{Mg}$ produced mainly acetone due to the presence of basic sites. Conversely, the catalyst with the largest amount of $\mathrm{Al}$ (i.e., $\mathrm{V} / \mathrm{Mg} 0.50 \mathrm{Al}$ ) enhanced the formation of propylene due to the presence of acid sites. Vanadium also contributed to the generation of further acid sites in the catalysts, thereby increasing the conversion of isopropanol to propylene [21].

Hydrotalcites with different $(\mathrm{Al} / \mathrm{Al}+\mathrm{Mg})$ ratios and prepared at different temperatures were also investigated in the isopropanol decomposition [22]. When the decomposition of isopropanol was carried out over calcined sample $\left(450{ }^{\circ} \mathrm{C}, 18 \mathrm{~h}\right)$, both acetone and propylene were observed. These results indicate that the calcined hydrotalcites exhibit both acid and basic sites [40]. Moreover, calcined hydrotalcites have basic sites capable of catalyzing consecutive reactions of acetone such as aldolic condensation and hydrogen transfer. It must be remarked that on the $\mathrm{MgO}$ prepared catalysts only acetone was detected as reaction product, and no further reaction of the primarily formed acetone was observed.

Furthermore, the presence of $\mathrm{Mg}$ almost inhibits the formation of propylene regardless of temperature. In addition, the existence of $\mathrm{Al}$ promotes a great formation of propylene due to the creation of new acid sites attributed to the substitution of $\mathrm{Mg}^{2+}$ by $\mathrm{Al}^{3+}$. A study of the catalytic conversion of the isopropanol reported that $\mathrm{V}-\mathrm{Mg}_{x} \mathrm{Al}$ catalyst with larger amount of $\mathrm{Mg}$ generated high selectivity of acetone. The greatest activity in the production of acetone in $\mathrm{V}-\mathrm{Mg}_{1.0} \mathrm{Al}$ catalyst is attributed to the presence of magnesium (basic sites). The same solid with large amount of $\mathrm{Al}$ 

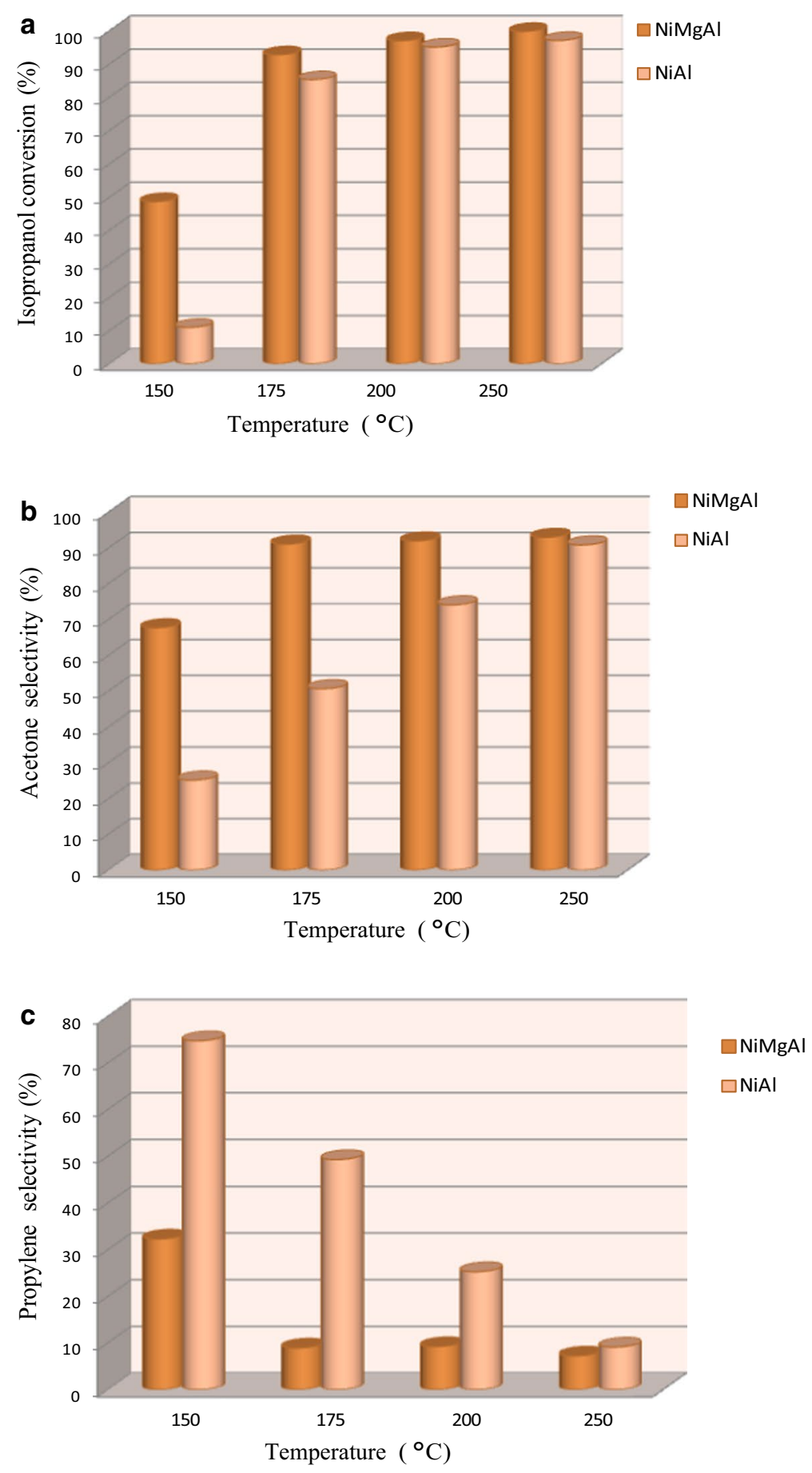
(i.e., $\mathrm{V}-\mathrm{Mg}_{0.5} \mathrm{Al}$ ) presented more selectivity to propylene due to the presence of a larger number of acid sites [1].

From the structural point of view, the number of defects, and therefore the number of strong basic sites, in the lattice of $\mathrm{MgO}$ should be expected to increase (or decrease?) when increasing the amount of $\mathrm{Al}_{2} \mathrm{O}_{3}$. On the other hand, an increase in $\mathrm{Al}$ should increase the average electronegativity of the solid and thus decreasing the average electronic density of the lattice oxygen since $\mathrm{Al}$ is more electronegative than $\mathrm{Mg}$. After calcination, XRD analysis showed the presence of $\mathrm{NiO}, \mathrm{MgO}$ and $\mathrm{Al}_{2} \mathrm{O}_{3}$ for NiMgAl-HTc and $\mathrm{NiO}$ and $\mathrm{Al}_{2} \mathrm{O}_{3}$ for NiAl-HTc. Since the solids were calcined at temperature $\left(450{ }^{\circ} \mathrm{C}\right)$ higher than the temperature of reaction $\left(150-250{ }^{\circ} \mathrm{C}\right)$, we suggest and expect no change in textural and structural properties during catalytic reaction. According to these factors, the changes in the catalytic activity of the catalysts would be due to the presence of different acid-base and redox properties. In our case NiMgAl-HT and NiAl-HT present different structural and textural properties due to the introduction of $\mathrm{Mg}$ into NiAl-HT matrix. They show different catalytic activity and acid-base properties during the catalytic decomposition of isopropanol.

At low reaction temperature (i.e., $150{ }^{\circ} \mathrm{C}$ ) the $\mathrm{NiAl}-\mathrm{CO}_{3}$-c catalyst shows acid sites owing to the main propylene formation. The selectivity to propylene reaches approx. $75 \%$.

Acetone is the only major product obtained for the two catalysts but by increasing the reaction temperature, an evolution of basic sites appeared on the surface of this sample to favor the acetone production so that the selectivity to acetone is $25.2 \%$ at $150{ }^{\circ} \mathrm{C}$ and increases up to $91 \%$ at $250{ }^{\circ} \mathrm{C}$, respectively.

Table 5 (or Fig. 12) shows the selectivity ratio (R) between acetone and propylene: $\left(R=\frac{\text { Acetone selectivity }}{\text { Propylene selectivity }}\right)$ for the samples and at different temperatures of the reaction.

Except for $\mathrm{NiAl}-\mathrm{CO}_{3}$-c catalyst at $150{ }^{\circ} \mathrm{C}$ in, the selectivity ratio $(R)$ resulted higher than 1 in both formulations (i.e., $\mathrm{NiMgAl}-\mathrm{CO}_{3}$ and $\mathrm{NiAl}-\mathrm{CO}_{3}$ ). Note that the ratio $R$ is more important for $\mathrm{NiMgAl}-\mathrm{CO}_{3}$, this result reveals clearly that the acetone is the predominant product owing to the significant basic properties of the sample NiMgAl- $\mathrm{CO}_{3}$-c. The difference in catalytic activity between $\mathrm{NiMgAl}-\mathrm{CO}_{3}-\mathrm{c}$ and $\mathrm{NiAl}-\mathrm{CO}_{3}-\mathrm{c}$ is related to textural and structural properties of the two solids since the crystallite size of $\mathrm{NiO}$ changes with the catalyst formulation (Table 5).

According to the literature [29, 36], NiMgAl-derived hydrotalcite catalyst shows higher activity than $\mathrm{NiAl}$ catalyst in the hydrogen generation via dry reforming of methane [20], an opposite trend was observed for $\mathrm{CoMgAl}$ and $\mathrm{CoAl}$ catalysts

Table 5 Selectivity ratio to acetone and propylene with structural parameters in the presence of the samples $\mathrm{NiMgAl}-\mathrm{CO}_{3}$-c and $\mathrm{NiAl}-\mathrm{CO}_{3}$-c catalysts

\begin{tabular}{|c|c|c|c|c|c|c|c|c|}
\hline \multirow[t]{2}{*}{ Catalyst } & \multirow[t]{2}{*}{ XRD phases } & \multirow{2}{*}{$\begin{array}{l}\text { Crystallites } \\
\text { size }(\AA)\end{array}$} & \multirow{2}{*}{$\begin{array}{l}\text { Surface } \\
\text { area }\left(\mathrm{m}^{2} / \mathrm{g}\right)\end{array}$} & \multicolumn{5}{|c|}{$R=\frac{\text { Acetone selectivity }}{\text { Propylene selectivity }}$} \\
\hline & & & & $T\left({ }^{\circ} \mathrm{C}\right)$ & 150 & 175 & 200 & 250 \\
\hline $\mathrm{NiMgAl}-\mathrm{CO}_{3}-\mathrm{c}$ & $\mathrm{NiO}, \mathrm{MgO}$ & 25.22 & 169 & - & 2.09 & 10.23 & 10.00 & 12.91 \\
\hline $\mathrm{NiAl}-\mathrm{CO}_{3}-\mathrm{c}$ & $\mathrm{NiO}$ & 35 & 117 & - & 0.33 & 1.02 & 2.93 & 9.98 \\
\hline
\end{tabular}




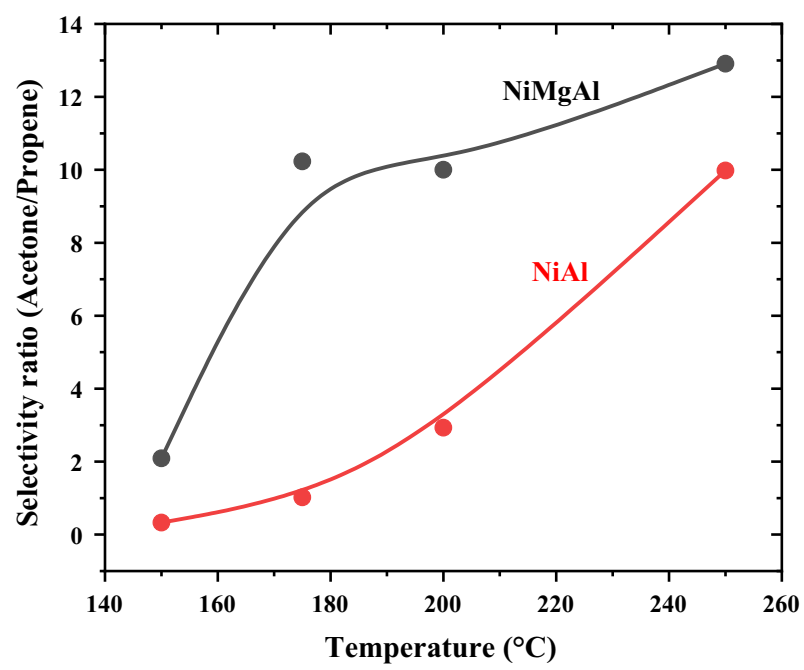

Fig. 12 Selectivity ratio to acetone and propylene $(R)$ for the $\mathrm{NiMgAl}-\mathrm{CO}_{3}$-c and $\mathrm{NiAl}-\mathrm{CO}_{3}$-c catalysts

derived from hydrotalcite [41]. In this work, $\mathrm{NiMgAl}-\mathrm{CO}_{3}-\mathrm{c}$ also presents the best and high catalytic activity in the isopropanol decomposition reaction and acetone production owing to its high surface area and a smaller crystallite size. This finding is due to the presence of $\mathrm{Mg}$ in the HDL phases which leads to increase in specific area with dispersive effect, formation of small species and favor strength of basic sites. The results showed a good correlation between the catalytic activity and the presence of basic sites created by the presence of $\mathrm{Mg}$ in the matrix $\mathrm{NiAl}$, the interaction between $\mathrm{MgO}$ and $\mathrm{Al}_{2} \mathrm{O}_{3}$ promotes the formation of suitable basic sites.

The basicity of HDL non-calcined phases is attributed to Bronsted basic sites of $\mathrm{HO}^{-}$hydroxide group located on the HDL network with weak strength. On the other hand, in the case of the mixed oxides $\mathrm{MgAl}-\mathrm{O}$, the strong basic sites, are Lewis type (i.e., $\mathrm{O}^{2-}$ and $\mathrm{M}^{2+}-\mathrm{O}_{2}$ ), without excluding the hydroxyl species, whose absorption bands have been observed on the infra-red spectra of the solid calcined at $450{ }^{\circ} \mathrm{C}$.

\section{Conclusions}

Two catalysts derived from hydrotalcite (i.e., $\mathrm{NiMgAl}-\mathrm{CO}_{3}-\mathrm{c}$ and $\mathrm{NiAl}-\mathrm{CO}_{3}$-c) were successfully prepared by coprecipitation method at $\mathrm{pH}$ basic constant ( $\mathrm{pH} 11)$. After their calcination at $450{ }^{\circ} \mathrm{C}$ for $6 \mathrm{~h}$, only single oxides were present in the samples. The characterization of fresh and calcined HDL phases using different methods of physical-chemical analysis, such as SAA, TGA/DTA, XRD, SEM, FTIR and RAMAN exhibited the features of HDL phases. The catalysts were tested for the isopropanol decomposition reaction at different reaction temperatures $(150,175$, 200 , and $250^{\circ} \mathrm{C}$ ). The solid $\mathrm{NiMgAl}-\mathrm{CO}_{3}$ - $\mathrm{C}$ demonstrated the best catalytic activity due to the presence of magnesium in the HDL phases structure. The incorporation of $\mathrm{Mg}$ into the HDL structure enhances the structural and textural properties so that 
a high surface area with a small crystallite size is obtained and strong basic sites are created over NiMgAl- $\mathrm{CO}_{3}$-c. To summarize, the study of the catalytic activity of isopropanol transformation showed that the catalytic performances and basic properties vary according to the following order: $\mathrm{NiMgAl}-\mathrm{CO}_{3}-\mathrm{c}>\mathrm{NiAl}-\mathrm{CO}_{3}-\mathrm{c}$.

Acknowledgements The authors acknowledge the financial support from the General Directorate for Scientific Research and Technological Development (DGRSDT), of the Algerian Ministry of Higher Education and Scientific Research.

Open Access This article is licensed under a Creative Commons Attribution 4.0 International License, which permits use, sharing, adaptation, distribution and reproduction in any medium or format, as long as you give appropriate credit to the original author(s) and the source, provide a link to the Creative Commons licence, and indicate if changes were made. The images or other third party material in this article are included in the article's Creative Commons licence, unless indicated otherwise in a credit line to the material. If material is not included in the article's Creative Commons licence and your intended use is not permitted by statutory regulation or exceeds the permitted use, you will need to obtain permission directly from the copyright holder. To view a copy of this licence, visit http://creativecommons.org/licen ses/by/4.0/.

\section{References}

1. F. Cavani, F. Trifirò, A. Vaccari, Catal. Today 11, 173 (1991)

2. S. Miyata, T. Kumura, Chem. Lett. 2, 843 (1973)

3. M.R. Othman, Z. Helwani, W.J.N. Fernando, Appl. Organomet. Chem. 23, 335 (2009)

4. A. Vaccari, Catal. Today 41, 53 (1998)

5. J.-M. Lavoie, Front. Chem. 2, 1 (2014)

6. Z. Abdelsadek, M. Sehailia, D. Halliche, V.M. Gonzalez-Delacruz, J.P. Holgado, K. Bachari, A. Caballero, O. Cherifi, J. CO2 Util. 14, 98 (2016)

7. Z. Abdelssadek, K. Bachari, A. Saadi, O. Cherifi, D. Halliche, Res. Chem. Intermed. 41, 1757 (2013)

8. P. Gao, R. Xie, H. Wang, L. Zhong, L. Xia, Z. Zhang, W. Wei, Y. Sun, J. CO2 Util. 11, 41 (2015)

9. L. Cocheci, P. Barvinschi, R. Pode, E. Popovici, E. Seftel, Chem. Bull. POLITEHNICA Univ. Timisoara 55, 40 (2010)

10. C. Forano, T. Hibino, F. Leroux, C. Taviot-Guého, Dev. Clay Sci. 1, 1021 (2006)

11. D. Haffad, A. Chambellan, J.C. Lavalley, J. Mol. Catal. A Chem. 168, 153 (2001)

12. J.C. Luy, J.M. Parera, Appl. Catal. 26, 295 (1986)

13. E. Ortiz-Islas, T. López, J. Navarrete, X. Bokhimi, R. Gómez, J. Mol. Catal. A Chem. 228, 345 (2005)

14. K. Von Tanabe, M. Misono, Y. Ono, H. Hattori, Angewandte Chemie, vol. 103 (1) (Elsevier, Amsterdam, 1989), pp. 114-115

15. J.M. Vohs, M.A. Barteau, Surf. Sci. 221, 590 (1989)

16. X. Gu, J. Ge, H. Zhang, A. Auroux, Thermochim. Acta 451, 84 (2006)

17. G.C. Bond, S.F. Tahir, Appl. Catal. 71, 1 (1991)

18. I.E. Wachs, Chem. Eng. Sci. 45, 2561 (1990)

19. T. Nakatsuka, K. Hitoshi, Y. Shinzo, K. Shinzo, Bull. Chem. Soc. Jpn. 52, 2449 (1979)

20. G. Fornasari, M. Gazzano, D. Matteuzzi, F. Trifirò, A. Vaccari, Appl. Clay Sci. 10, 69 (1995)

21. D. Meira, G. Cortez, W. Monteiro, J. Rodrigues, Braz. J. Chem. Eng 23, 351 (2006)

22. A. Corma, V. Fornes, F. Rey, J. Catal. 148, 205 (1994)

23. A. Bhattacharyya, V. Chang, D. Schumacher, Appl. Clay Sci. 13, 317 (1998)

24. A. Monshi, M.R. Foroughi, M.R. Monshi, World J. Nano Sci. Eng. 02, 154 (2012)

25. F.T.L. Muniz, M.A.R. Miranda, C. Morilla dos Santos, Acta Crystallogr. A Found. Adv. 72, 385 (2016)

26. D. Tichit, C. Gérardin, R. Durand, B. Coq, Top. Catal. 39, 89 (2006) 
27. E. Kanezaki, Solid State Ion. 106, 279 (1998)

28. M. Crivello, C. Pérez, J. Fernández, G. Eimer, E. Herrero, S. Casuscelli, E. Rodríguez-Castellón, Appl. Catal. A Gen 317, 11 (2007)

29. Z. Abdelsadek, J.P. Holgado, D. Halliche, A. Caballero, O. Cherifi, S. Gonzalez-Cortes, P.J. Masset, Catal. Lett. 151, 2696 (2021)

30. J. Pérez-Ramırez, G. Mul, J. Moulijn, Vib. Spectrosc. 27, 75 (2001)

31. C. Forano, U. Costantino, V. Prévot, C.T. Gueho, J. Mater, vol. 5 (Elsevier, Amsterdam, 2013), pp. $745-782$

32. M. Nawfal, C. Gennequin, M. Labaki, B. Nsouli, A. Aboukais, E. Abi-Aad, Int. J. Hydrog. Energy 40, 1269 (2015)

33. P. Bera, M. Rajamathi, M. Hegde, P.V. Kamath, Bull. Mater. Sci. 23, 141 (2000)

34. K.L. Erickson, T.E. Bostrom, R.L. Frost, Mater. Lett. 59, 226 (2005)

35. J.T. Kloprogge, D. Wharton, L. Hickey, R.L. Frost, Am. Mineral. 87, 623 (2002)

36. X. Zhang, L. Zhang, H. Peng, X. You, C. Peng, X. Xu, W. Liu, X. Fang, Z. Wang, N. Zhang, X. Wang, Appl. Catal. B Environ. 224, 488 (2018)

37. A.C.C. Rodrigues, C.A. Henriques, J. Mater. Res. 6, 563 (2003)

38. R. Benrabaa, H. Boukhlouf, A. Löfberg, A. Rubbens, R.-N. Vannier, E. Bordes-Richard, A. Barama, J. Nat. Gas Chem. 21, 595 (2012)

39. A. Gervasini, J. Fenyvesi, A. Auroux, Catal. Lett. 43, 219 (1997)

40. A.L. McKenzie, C.T. Fishel, R.J. Davis, J. Catal. 138, 547 (1992)

41. Z. Abdelsadek, P. Chaudhari, J.P. Holgado, F. Bali, D. Hallcihe, O. Cheifi, S. Gonzalez-Cortes, P.J. Masset, I.O.P. Conf, Ser. Earth Environ. Sci. 880, 1 (2021)

Publisher's Note Springer Nature remains neutral with regard to jurisdictional claims in published maps and institutional affiliations. 